\title{
Origins of carbon sustaining the growth of whitefish Coregonus lavaretus early larval stages in Lake Annecy: insights from fatty-acid biomarkers
}

\author{
M.-E. Perga*†, A. Bect and O. Anneville* \\ *UMR CARRTEL INRA, Station d'Hydrobiologie Lacustre, 75 avenue de Corzent, \\ BP 511, 74203 Thonon les Bains cedex, France and †Université Blaise Pascal, 34, \\ avenue Carnot - BP 185, 63006 Clermont-Ferrand Cedex, France
}

(Received 10 February 2008, Accepted 22 September 2008)

\begin{abstract}
The hypothesis that diatom carbon (C) produced during the spring peak supported spring zooplankton production and, ultimately, the growth of Coregonus lavaretus early larval stages from March to May 2006 in Lake Annecy, France, was tested using gut content analyses and fatty acid biomarkers. Gut content results showed that $C$. lavaretus larvae from stages 1 to 4 preferentially fed on copepods with Daphnia sp. only a minor proportion of larval diet. The levels of diatom-marker fatty acids (C16:1n-7 and C20:5n-3) were high in Daphnia sp., but lower in both copepods and $C$. lavaretus larvae from stages 0 to 4 . These results indicated that the spring diatom biomass was actually grazed by Daphnia sp., but, contrary to what was expected, the spring bloom was not the only $\mathrm{C}$ source supporting copepods secondary production and, consequently, the growth of $C$. lavaretus early larval stages. In contrast, levels of terrestrial fatty acid marker (C24:0) were low in Daphnia sp. but high in copepods and C. lavaretus larvae, indicating a significant contribution of terrestrial carbon to copepods and, ultimately, to the growth of C. lavaretus early larval stages.

(C) 2009 The Authors

Journal compilation (C) 2009 The Fisheries Society of the British Isles
\end{abstract}

Key words: copepods; Daphnia; diatoms; food web; lake; terrestrial carbon.

\section{INTRODUCTION}

Fish recruitment success is very strongly influenced by survival at the early larval stages (Bradford \& Cabana, 1997). Thus, the origins of the carbon sources sustaining the growth of the early larval stages may be a crucial factor controlling fish dynamics. Recent studies in marine environment demonstrated that the survival and physiological conditions of larval fishes depend on both the specific composition (St John \& Lund, 1996; Rossi et al., 2006) and the timing of the local spring phytoplankton bloom (Beaugrand et al., 2003; Platt et al., 2003).

$\dagger$ Author to whom correspondence should be addressed. Tel.: +33 450267818; fax: +33 450260760; email: perga@thonon.inra.fr 
In lakes, there is growing evidence that food webs can be fuelled by carbon (C) sources of various origins (phytoplankton-derived $v$. terrestrial-derived C; Carpenter et al., 2005). The relative contributions of terrestrial-derived and phytoplankton-derived $\mathrm{C}$ to lake zooplankton, benthos and fish secondary production have been more thoroughly investigated recently, strongly benefiting from the development of stable-isotope and fatty-acid techniques (Karlsson et al., 2003; Carpenter et al., 2005; Perga et al., 2006). Still, little attention has been dedicated to the identification of the carbon sources that could sustain the growth of fish early larval stages in lakes.

The whitefish Coregonus lavaretus (L.) constitutes a major fisheries resource in European subalpine lakes. In Lake Annecy, France, $C$. lavaretus catches by anglers and professional fishermen reach 20-30 $\mathrm{t}_{\text {year }}^{-1}$, i.e. $8-11 \mathrm{~kg} \mathrm{ha}^{-1}$, far above catches of Arctic charr Salvelinus alpinus (L.), perch Perca fluviatilis L. or brown trout Salmo trutta L. (SILA, 2007). Coregonus lavaretus spawn in late December and their eggs hatch in late February (Anneville et al., 2007). In French subalpine lakes such as Lake Annecy, C. lavaretus feed essentially on zooplankton for its whole life (Perga \& Gerdeaux, 2005; Anneville et al., 2007). Phytoplankton blooms occurs in late winter to early spring, and diatoms largely dominate at this time of the year (SILA, 2007). Phytoplankton biomass is higher during the spring bloom than at any other period of the year (e.g. 2006; Fig. 1 from SILA, 2007). Thus diatom $\mathrm{C}$ produced during this spring bloom was expected to strongly support spring zooplankton production and, ultimately, the growth of $C$. lavaretus early larval stages from March to May in Lake Annecy. Hence, terrestrial-derived $\mathrm{C}$ contribution to $C$. lavaretus larvae growth during spring phytoplankton bloom should be negligible.

This hypothesis was tested using fatty-acid (FA) biomarkers. The fatty-acid trophic marker concept is based on the observation that $\mathrm{C}$ sources of different origins and natures lay down certain fatty-acid patterns that may be

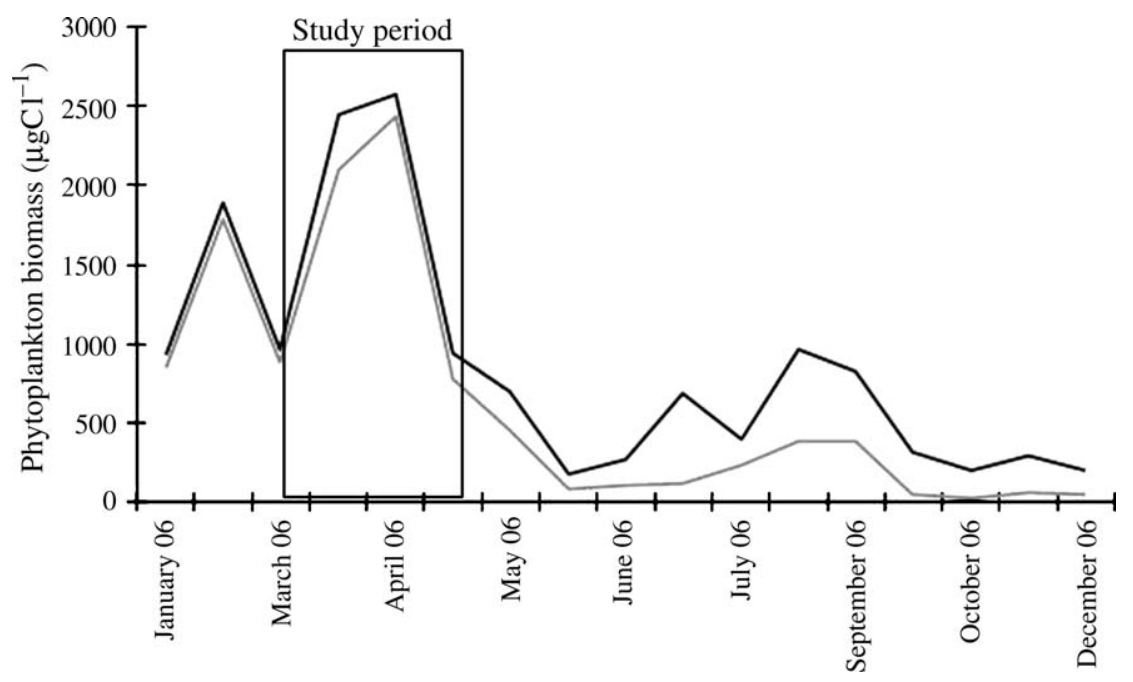

FIG. 1. Seasonal changes in total phytoplankton biomass (-) and diatoms biomass (-) in Lake Annecy in 2006 (from SILA, 2007). 
transferred conservatively to, and hence can be recognized, in consumers (Dalsgaard et al., 2003). Among these source-marker FAs, high levels of C16:1n-7 and of 20:5n-3 are typical of diatoms (Sargent et al., 1987; St John \& Lund, 1996; Parrish et al., 2000). Chlorophytes are characterized by important concentrations of $16 \mathrm{C}$ and $18 \mathrm{C}$ polyunsaturated fatty acids (PUFA) (Ahlgren et al., 1992; Sargent et al., 1995). Cryptophytes and dinophytes contain also $18 \mathrm{C}$ n-3 PUFA and exhibit particularly high amounts of highly unsaturated fatty acids (HUFAs) such as eicosapentaenoic acid (EPA) (20:5n-3) and docosahexaenoic acid (DHA) (22:6n-3) (Ahlgren et al., 1990; Napolitano, 1998). Carbon processing through the microbial loop and subsequent zooplankton consumption of micro-organisms might be traced from bacterial FA [BAFA_odd-saturated and branched-chain FA, i.e. the sum of C15:0 and C17:0 and their iso-series and anteiso-series (Ederington et al., 1995; Desvilettes et al., 1997; Bec et al., 2003; Perga et al., 2006)]. In contrast, long-chain FAs, such as lignoceric acid (C24:0), are typical of terrestrial plants (Sun et al., 2000). Hence, FA composition of zooplankton and fish larvae would provide information on the carbon sources that actually sustained zooplankton secondary production and, ultimately, $C$. lavaretus growth during the study period.

Furthermore, the availability of HUFA and especially EPA and DHA is of prime importance for larval development and fitness (Sargent et al., 1999). Larval behaviour, growth rate and ability to feed as well as development of the brain and nervous systems are strongly dependant on levels of EPA and DHA provided by the diet (Ishizaki et al., 2001). Therefore, the retention and accumulation of these essential FA (EFA) in the early larval stages are key factors in fish recruitment fluctuations (Bell \& Sargent, 1996; St John et al., 2001).

As EFAs are preferentially retained in zooplankton and fishes (Kainz et al., 2004), they are not transferred conservatively between the food source and the prey, which could hence limit their reliability as fatty acid trophic markers. Therefore, in this study, only non-essential FAs (C16:1n-7, BAFA and C24:0) were employed as trophic markers. EPA and DHA, available for fish larvae, however, are strongly dependant on the primary $\mathrm{C}$ source at the base of the food chain and on the trophic pathways conveying this carbon up to larval fishes (St John et al., 2001). EPA and DHA levels were thus additionally measured in order to document how zooplankton and larvae EPA and DHA content could be related to the $\mathrm{C}$ sources fuelling the food chain.

\section{MATERIALS AND METHODS}

\section{STUDY SITE}

Lake Annecy $\left(45^{\circ} 54^{\prime} \mathrm{N} ; 06^{\circ} 08^{\prime} \mathrm{E}\right)$ is located on the western border of the Alps, in the south-east part of France (altitude $446 \mathrm{~m}$ ). Its catchment area is $302 \mathrm{~km}^{2}$, its surface area $28 \mathrm{~km}^{2}$ and its maximum depth is $65 \mathrm{~m}$. It is a clear-water, oligotrophic lake, with an average total phosphorus concentration of $6 \mu \mathrm{gP} 1^{-1}\left(1-2 \mu \mathrm{gP} 1^{-1}\right.$ from orthophosphates) and an average annual transparency of $7 \mathrm{~m}$. Lake Annecy is subjected to a monthly 
or bimonthly biomonitoring, which is carried out the Syndicat Intercommunal du Lac d'Annecy (SILA).

\section{SAMPLING}

In 2006, phytoplankton was sampled every 2 weeks during the routine lake biomonitoring (SILA, 2007). Integrated samples of $20 \mathrm{~m}$ depth were collected using a Pelletier bottle. Samples were preserved in lugol and counted under an inverted microscope according to the Ütermohl technique (Ütermohl, 1958). Counts were converted to g C $1^{-1}$ according to Wetzel \& Likens (2000). Algae with cell or colony size $<20 \mu \mathrm{m}$ were considered as nanophytoplankton, while those $>20 \mu \mathrm{m}$ were classified as microphytoplankton.

Zooplankton and $C$. lavaretus larvae sampling was carried out weekly from the end of February until the beginning of May. The larvae were collected early morning in the littoral zone of Lake Annecy using two rectangular $1 \mathrm{~mm}$ mesh nets (width $=1.5 \mathrm{~m}$, height $=1.0 \mathrm{~m}$ and length $=5.0 \mathrm{~m}$ ) towed on both sides of a motor boat. On the boat, larvae collected were maintained in lake water, and kept on ice to limit digestion and lipolytic degradation. At the laboratory, larvae were quickly measured and sorted according to their larval developmental stage (Luczynski et al., 1988) and instantaneously frozen in a $-80^{\circ} \mathrm{C}$ cryogenic freezer.

Zooplankton was sampled at a sampling station located near the area of larvae sampling. Zooplankton was collected with a $200 \mu \mathrm{m}$ mesh-size zooplankton net with four vertical hauls. Samples intended for zooplankton counts were fixed using $5 \%$ formalin. Samples intended for fatty-acid analyses were preserved on ice until sorted in the laboratory.

Formalin-preserved zooplankton samples were counted under a dissecting microscope. Zooplankton samples intended for fatty-acid analyses were sorted according to three categories: Daphnia sp. and cyclopoids (Cyclops prealpinus and Mesocyclos leuckartii) of large $(>500 \mu \mathrm{m})$ and small $(<500 \mu \mathrm{m})$ size. Calanoids were not included in this study as they contributed to $<5 \%$ of total crustaceans at the study time and were rare in C. lavaretus larvae gut contents (Anneville et al., 2007).

\section{STOMACH CONTENTS}

Larval diets were evaluated by dissecting the entire gut contents. Prey were identified and counted at the group level under a microscope.

\section{FATTY-ACID ANALYSIS}

Fatty-acid analyses were performed from freeze-dried zooplankton and fish larvae samples (1-5 mg). Tricosanoic acid (C23:0) was added as an internal standard. Briefly, the lipids were extracted using a 4:2:1 chloroform:methanol:water mixture. The FAs, analysed as methyl esters (FAME), were prepared by saponification of the lipid extract $\left(\mathrm{NaOH}-\mathrm{CH}_{3} \mathrm{OH} 2 \mathrm{~N}\right)$ followed by esterification $\left(\mathrm{H}_{2} \mathrm{SO}_{4}-\mathrm{CH}_{3} \mathrm{OH} 2 \mathrm{~N}\right)$. The FAME extract was subsequently analysed by gas chromatography (GC-2010; Shimadzu, Kyoto, Japan) on a Supelcowax 10 capillary column $(30 \mathrm{~m}, 0.25 \mathrm{~mm}$ inner diameter and $0.25 \mu \mathrm{m}$ film thickness) and measured by a flame ionization detector (FID). The FAME were identified by comparison of their retention times with known standards (37-component FAME mix, Supelco 47885-U; bacterial fatty acid methyl esters mix, Supelco 47080-U; Supelco, Bellefonte, PA, U.S.A.) and quantified with reference calibration curves derived from $2 \cdot 5,50,100,250,500,1000$ and $2000 \mathrm{ng}^{-1} \mathrm{l}^{-1}$ solutions of the FAME standards.

As total FA absolute amounts vary substantially between zooplankton and fish larvae or between different larval stages as a result of changes in total lipid content, FAs were reported as per cent mass of the total identified FAs. Once reported as percentages, FA amounts are dependent on each other. For instance, an increased amount 
from a single FA between two larval stages would necessarily result in a decreased percentage of the others even if their absolute amounts did not change. In order to avoid these pitfalls, source indexes were used that compare the amount of a marker FA to the amount of palmitoleic acid, which is quite ubiquitous in phytoplankton. Thus, the (C16:1n-7) : (C16:0) ratio has been used as an index of diatom $\mathrm{C}$ transfer in zooplankton and fish larvae (St John \& Lund, 1996; Dalsgaard et al., 2003). The (C24:0) : (C16:0) ratio was used to track terrestrial-derived $\mathrm{C}$ transfer and (BAFA) : (C16:0) to document the involvement of the microbial loop in transferring $\mathrm{C}$ from primary producers to zooplankton and, ultimately, C. lavaretus larvae.

\section{DATA ANALYSIS}

Differences in gut content compositions between larval stages were detected using $\chi^{2}$ tests on contingence tables. General FA patterns were investigated using normalized principal component analysis (PCA). Variations in FA amounts or ratios between prey taxa and larval stages were indicated using non-parametric Kruskal-Wallis (KW) tests, as variances were not always homogenous between groups (prey taxa and larval stages). Post hoc multiple comparisons were run using Dunnett's test as it has no requirement for homogeneity of variances. Relationships between FA amounts or indexes were investigated using correlations and ANCOVA to detect potential interactions between the descriptors. All statistical tests were performed on S-Plus statistical software.

\section{RESULTS}

\section{PHYTOPLANKTON BIOMASS, ZOOPLANKTON ABUNDANCE AND COMPOSITION}

During the study period, diatoms contributed to $65-95 \%$ of phytoplankton carbon biomass, and were predominant in the microphytoplankton size fraction, contributing to $73-96 \%$ of its biomass [Fig. 2(a)]. Diatoms were less abundant in nanophytoplankton, representing 25-60\% of its biomass [Fig. 2(b)]. Microphytoplankton prevailed over nanophytoplankton, representing between 80 up to $96 \%$ of total phytoplankton carbon biomass. Cyclotella cyclopuncta was the dominant diatom taxon within nanoplankton, while cryptophytes were essentially composed of Rhodomonas minuta and dinophytes of Peridinium

(a)

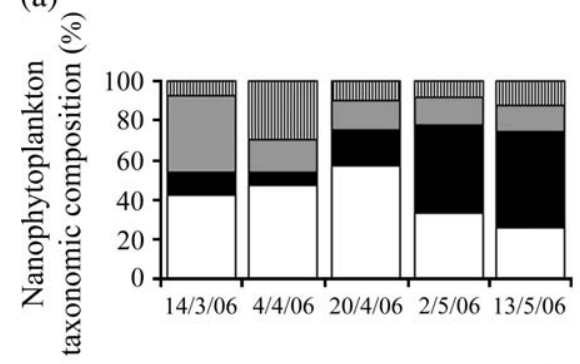

(b)

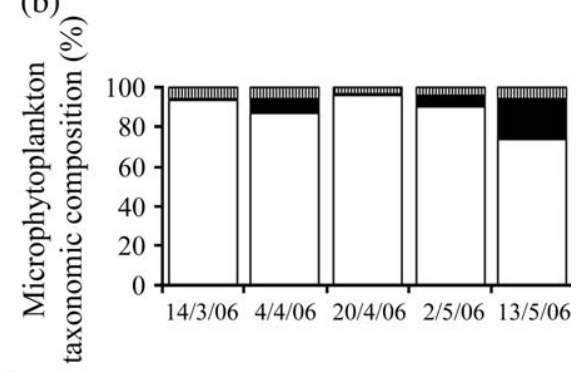

Sampling dates

FIG. 2. Proportions of diatoms $(\square)$, dinophytes $(\square)$, cryptophytes $(\square)$ and other algae (四) in the (a) nanophytoplankton $(<20 \mu \mathrm{m})$ and (b) microphytoplankton $(>20 \mu \mathrm{m})$ in Lake Annecy at the sampling dates. 
cunningtonii and Gymnodinium sp. Within microphytoplankton, dominant diatoms were essentially represented by Asterionella formosa and Fragilaria crotonensis and dinophytes by Ceratium hirundinella.

Copepods dominated zooplankton representing between 59 and $88 \%$ of crustacean abundance, while Daphnia sp. contributed to 3-33\% over the study period (Fig. 3).

\section{FISH LARVAE CAPTURES AND GUT CONTENTS}

Stage 0 larvae could be caught for the first time in late February (21 February) and stage 1 larvae, corresponding to the first feeding stage, were captured for the first time on 15 March. Captures at the last sampling date (10 May) were still composed of larvae of stages $1-4$. The sampling method used for this study was not efficient at catching $C$. lavaretus larvae of stages $>4$.

Only individuals for which $>90 \%$ of prey items could be identified were kept in this analysis. As the number of prey items per individuals was low, the number of items counted for each prey taxon was summed for all individuals of the same larval stage, and diet composition was compared between larval stages. Diet composition changed significantly between stages (d.f. $=3, P<0.001$ ). Copepods were the major prey taxa for $C$. lavaretus larvae at all stages, but the proportion of Daphnia sp. in guts increased regularly from stage 1 $(<4 \%)$ to $4(38 \%)$ (Fig. 4$)$.

\section{GENERAL FATTY-ACID PATTERNS}

The amounts of the main FAs identified for the prey taxa and larval fish stages are given in Table I. In zooplankton and fish larvae, the ubiquitous C16:0 was always the dominant FA. Other major FAs were C20:5n-3 (EPA), C18:1n-9, C16:1n-7 and C18:3n-3 in Daphnia sp. 22:6n-3 (DHA), EPA and C18:2n-6 in small and large copepods and C18:1n-9, DHA and EPA in fish larvae. The DHA levels were very low in Daphnia sp. FAs included in the PCA

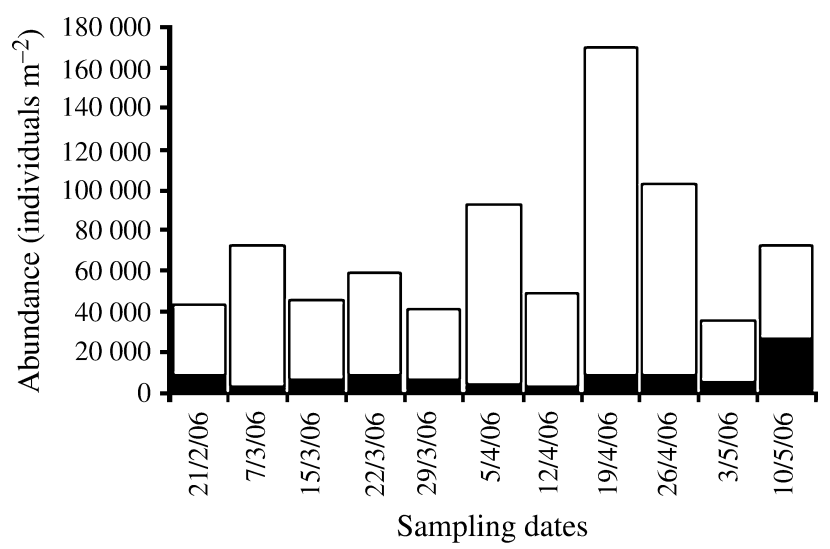

FIG. 3. Copepods $(\square)$ and Daphnia sp. abundance in Lake Annecy at the sampling dates. 


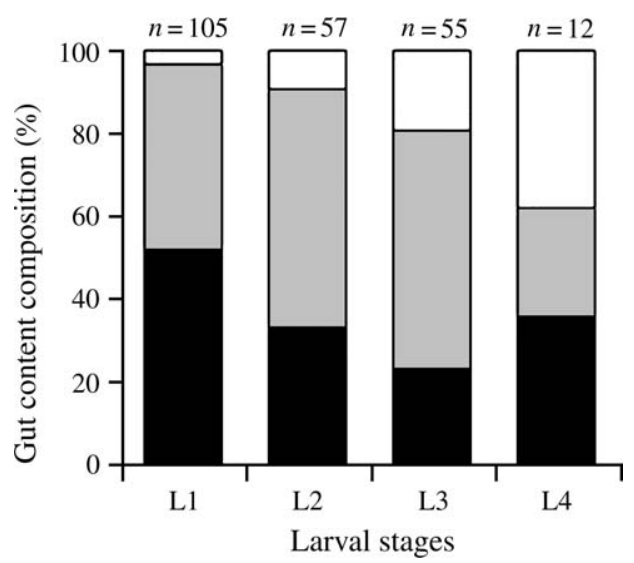

FIG. 4. Proportions of Daphnia sp. ( $\square$ ), small copepods ( and large copepods $(\square)$ in the gut contents of Coregonus lavaretus larvae from stage 1 (L1) to stage 4 (L4) for the study period.

analysis were targeted for their potential role as trophic markers or as EFA [BAFA, C16:1n-7, C24:0, C18:4n-3, C18:3n-3 and EPA (DHA was excluded as it was present at very low concentrations in Daphnia sp.)].

The two first components of the PCA accounted for $78 \%$ of total variability. C18:3n-3, C16:1n-7, C18:3n-4, C24:0 and EPA had the highest loadings on the first principal component (PC), with a positive correlation for C24:0 and a negative one for C18:3n-3, C18:4n-3, C16:1n-7 and EPA (Fig. 5). The BAFA had the highest loadings on the second PC. Samples scores on the first PC made it possible to distinguish Daphnia sp. with the most negative scores $(<-1 \cdot 5)$, indicating that they were enriched in EPA and C16:1n-7. Copepods scores were more positive (from -2 to 2), illustrating they were depleted in these FAs and had a higher content in the terrestrial biomarker C24:0 relatively to Daphnia sp. Fish larvae had the most positive scores $(>-1)$ and hence the lowest amount in EPA and diatom biomarkers and the highest content in the terrestrial biomarker. The second component essentially accounted for the variability in FA composition amongst larvae samples (Fig. 5).

\section{FATTY-ACID COMPOSITION OF THE PREY TAXA}

Analyses of individual fatty acids confirmed that Daphnia sp. were significantly enriched in EPA compared to copepods of both size-classes (Table II and Fig. 6). Values for the diatom index [(C16:1n-7) : (C16:0)] were also significantly higher in Daphnia sp. In contrast, copepods were enriched in DHA and had higher values for the terrestrial index compared to Daphnia sp. No differences in the bacterial index values amounts could be detected between prey taxa. Post hoc tests detected no significant differences in the amounts of all targeted FA or indexes values between copepods of the small and large size-classes.

Amounts of EPA and values for the diatom index were positively related for prey taxa $\left(r^{2}=0.657, P<0.001\right)$, such as the terrestrial and bacterial indices $\left(r^{2}=0.46, P<0.001\right.$; Fig. 7). The ANCOVA analyses revealed that both 


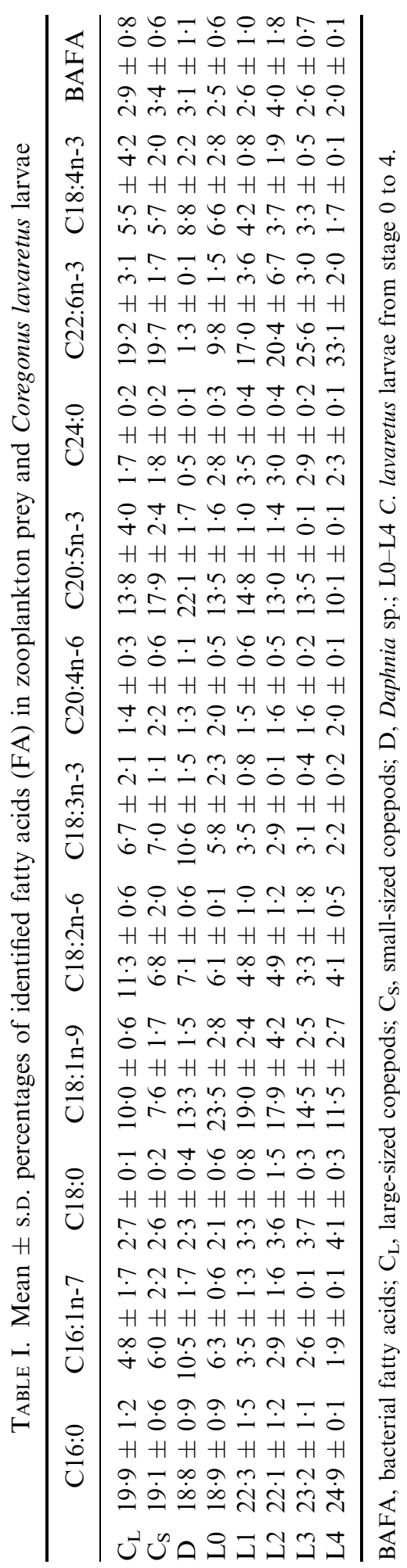



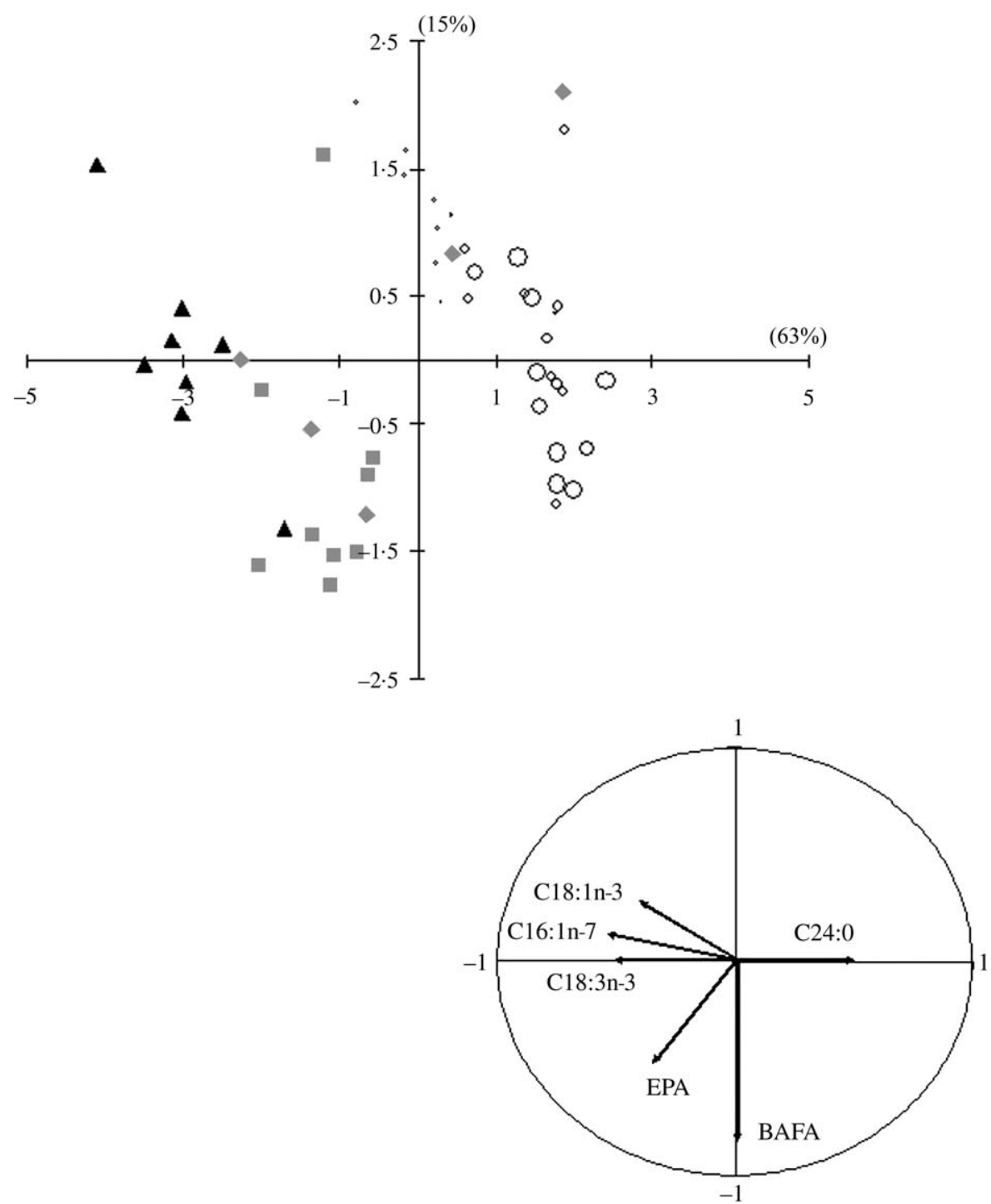

FIG. 5. Results from the principal component analyses on fatty-acid compositions of the prey [Daphnia sp.

$(\mathbf{A})$ large-sized $(\diamond)$ and small-sized $(\square)$ copepods] and Coregonus lavaretus larvae from stages $0(\bullet), 1$ $($ ()), $2(0)$ and 3 plus $4(0)$ (EPA, eicosapentaenoic acid; BAFA, bacterial fatty acids).

relationships depended on the considered prey taxa $\left(F_{2,20}, P=0 \cdot 01\right.$ and $F_{2,20}$, $P<0.001$ for diatom and terrestrial indices, respectively). DHA content was not related to any of the indices.

\section{FATTY-ACID COMPOSITION OF C. LAVARETUS LARVAE}

All targeted FA or indexes displayed significant changes during larval development, except for the bacterial index (Table II). The EPA relative amounts, 
TABLE II. Differences in fatty acid (FA) per cent amounts and FA indices for zooplankton prey and larval stages of Coregonus lavaretus

\begin{tabular}{|c|c|c|c|c|}
\hline \multirow[b]{2}{*}{ FA variations } & \multicolumn{2}{|c|}{ Between zooplankton prey taxa } & \multicolumn{2}{|c|}{ Between C. lavaretus larval stages } \\
\hline & $\mathrm{KW} \chi^{2}$ value & $P$ & $\mathrm{KW} \chi^{2}$ value & $P$ \\
\hline EPA & $16 \cdot 3$ & $<0.001$ & $10 \cdot 8$ & $<0 \cdot 05$ \\
\hline DHA & $15 \cdot 0$ & $<0.001$ & $23 \cdot 2$ & $<0.001$ \\
\hline Diatom index & $12 \cdot 5$ & $<0.001$ & $20 \cdot 3$ & $<0 \cdot 001$ \\
\hline Terrestrial index & $14 \cdot 0$ & $<0 \cdot 001$ & $16 \cdot 7$ & $<0 \cdot 001$ \\
\hline Bacterial index & 0.6 & $>0 \cdot 05$ & $4 \cdot 0$ & $>0 \cdot 05$ \\
\hline
\end{tabular}

DHA, docoshexaenoic acid; EPA, eicosapentaenoic acid; KW, Krustal-Wallis test.

similar to the terrestrial, diatom indexes decreased from stage 0 to 4 (Fig. 6). For all FA or ratios, except EPA and DHA, the significant changes occurred between stages 0 (no feeding) and 1, while FA amounts or ratios remained similar from stages 1 to 4 . In contrast, the significant decrease in EPA occurred between stages 3 and 4. For the latest stages, the amounts of EPA such as the values for all the indices were similar to those in copepods. For DHA, amounts increased continuously from stages 0 to 4 , with significantly higher DHA relative amounts in $\mathrm{L} 4$ than those of the prey taxa $(\mathrm{KW}$, d.f. $=4$, $P=0 \cdot 01)$.

\section{DISCUSSION}

The major marine fish stocks in the world are located in upwelling regions in which the injection of nitrate from deep water layers stimulates high diatom productions. These systems are characterized by short food chains in which the diatom $\mathrm{C}$ is transferred to large copepods and then finally to fish larvae (St John et al., 2001). These diatom-based food chains are thought to enhance the physiological condition of larval fishes, such as North Sea cod Gadus morhua L. (St John \& Lund, 1996) or anchovy Engraulis encrasicolus (L.) (Rossi et al., 2006) and thus recruitment. As spring primary production in Lake Annecy is largely dominated by diatoms, consistent with what has been observed in marine areas, diatoms should be the ultimate carbon source sustaining the growth of $C$. lavaretus early larval stages.

\section{ZOOPLANKTON FOOD WEB}

In Lake Annecy in 2006, although the spring diatom bloom reached relatively high biomasses that lasted for nearly 3 months, no clear peak in zooplankton abundance could be detected. High (C16:1n-7) : (C16:0) ratios in Daphnia sp., however, attested they were actually grazing on diatoms. Yet Daphnia sp. remained at a low level in the crustacean zooplankton population at this period of time, and $C$. prealpinus was strongly dominant. Copepods are omnivorous and tend to become carnivorous when they get older (Kerfoot \& Kirk, 1991). Therefore, it would be expected that small copepods would graze 

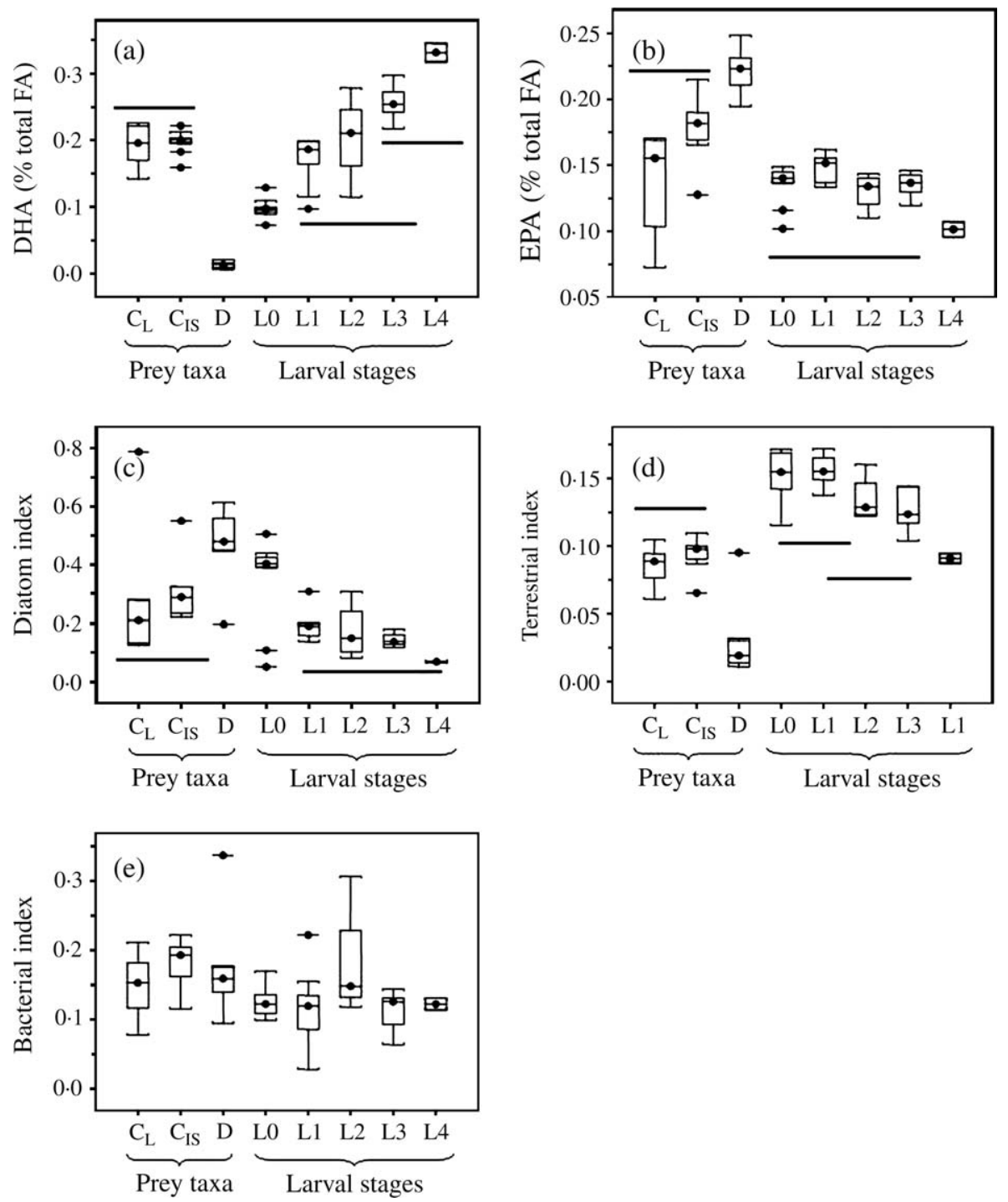

FIG. 6. Boxplot representations (the box represents the inter-quartile range, the bar with the box the median value, the mean, I 95\% CI and the outside points are outliers) of the values of (a) per cent amounts of docosahexaenoic (DHA) and (b) eicosapentaenoic acid acid (EPA) and (c) diatom, (d) terrestrial and (e) bacterial indices in the zooplankton prey [Daphnia sp. (D) large-sized $\left(\mathrm{C}_{\mathrm{L}}\right)$ and small-sized $\left(\mathrm{C}_{\mathrm{S}}\right)$ copepods] and Coregonus lavaretus larvae from stage 0 (L0) to stage 4 (L4). The horizontal bars indicate homogeneous groups of means.

on diatoms. For the larger ones, the diatom biomarker $\mathrm{C} 16: 1 \mathrm{n}-7$ could have been expected to be transferred from the copepods' prey, which would have been grazing on diatoms. In contrast, low values for the $\mathrm{C} 16: 1 \mathrm{n}-7: \mathrm{C} 16: 0$ ratio in copepods from both size-classes suggested that copepod secondary production only moderately benefited from direct grazing on diatoms. The relatively low reliance of copepods of both size-classes on diatom-derived $\mathrm{C}$ may explain why the 

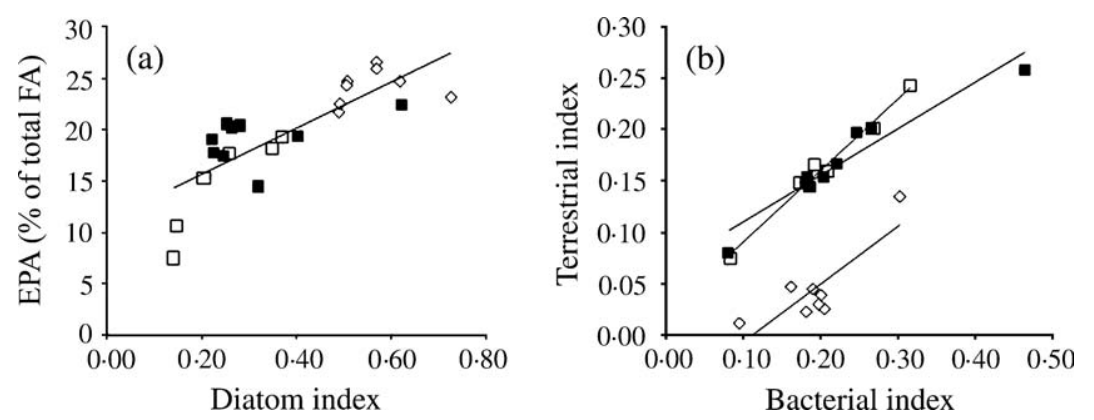

FIG. 7. Relationships between (a) the value of the diatom index and eicosapentaenoic acid (EPA) content and (b) the value of the terrestrial and bacterial indexes, in Daphnia sp. $(\diamond)$, large-sized $(\square)$ and small-sized ( $\square$ ) copepods. The curves were fitted by: (a) $y=12 \cdot 3 x+16 \cdot 3$ and (b) Daphnia sp. $y=$ $0 \cdot 35 x-0.03$ and large-sized and small-sized copepods $y=0 \cdot 29 x+0 \cdot 04$.

high diatom primary production did not result in a peak in copepod abundance in the spring, although other factors, such as temperature or fish predation, might be involved. High (C24:0) : (C16:0) ratios in copepods compared to Daphnia sp. would attest of their significant reliance on terrestrial-derived carbon. The positive correlation between BAFA and C24:0 would suggest that terrestrial-derived and bacterial-derived $\mathrm{C}$ were co-transferred either because copepods grazed on terrestrial particles on which bacteria grew or because copepods switched to the microbial loop (bacterivorous protists) and terrestrial particles when phytoplankton $\mathrm{C}$ was limiting.

The spring bloom in Lake Annecy in 2006 was largely dominated by microplanktonic species, and especially A. formosa and $F$. crotonensis, which are large, colonial diatoms $(>40 \mu \mathrm{m})$. This size belongs to the range of edible particles for Daphnia sp. (Burns, 1968) but might be beyond the range of size of grazable particles for copepods nauplii and copepodites (Kerfoot \& Kirk, 1991). Only nanoplanktonic diatom species might have been grazed by copepods, while Daphnia sp. could benefit from diatom production as well in the microplankton size fraction.

The positive correlation between the diatom index and EPA levels in crustacean zooplankton suggested that diatoms were the source of EPA in this food chain (Pohl \& Zurheide, 1979). Depletion in diatom biomarkers in copepods suggested that lower levels of EPA in copepods compared to Daphnia sp. were the consequences of diet differences between the two taxa and the copepods' lower reliance on diatoms, rather than from differences in accumulation rates of this FA (Farkas et al., 1981). In contrast, differences in DHA amounts between Daphnia sp. and copepods cannot be related to feeding differences. Indeed, Daphnia sp. do not accumulate DHA despite its occurrence in their diet (Brett et al., 2006). In addition, this pattern, observed for DHA, might also occur for other FAs. Nevertheless, knowledge is clearly lacking on that point as, so far, experiment studies on zooplankton (and especially copepods) fed known diets are scarce and mainly focused on EFA. For instance, Daphnia sp. fed terrestrial organic matter would not retain $\mathrm{C} 24: 0$ in their polar lipids (M. Brett, pers. com.). This result would not impair the present study as it 
would only suggest that terrestrial C contribution to Daphnia sp. was even underestimated during the diatom spring peak. It yet stresses the necessity for further experiment studies comparing copepods and Daphnia sp. ability to retain non-essential and source-specific FAs.

\section{CARBON SOURCES SUSTAINING THE GROWTH OF C. LAVARETUS LARVAE}

In this survey, the FA composition of $C$. lavaretus larvae fairly matched that of their food source, especially for non-essential FA (C16:1n-7, C24:0 and BAFA), thus validating the approach by FA trophic biomarkers. The observed incorporation of zooplankton FAs into $C$. lavaretus larvae lipids was consistent with observations previously done on other freshwater fishes, e.g. pike Esox lucius L. larvae (Desvilettes et al., 1994) and Vendace Coregonus albula (L.) $0+$ years of age (Muje, 1989).

The FA composition at stage 0 was substantially different from that at older stages. At stage 0, larvae do not have exogenous feeding and stage 0 larvae (L0) FAs are provided by hydrolysis of the yolk-sack lipids. Then, their FA composition reflects that of the yolk sac (Desvilettes et al., 1994). Relative richness in C24:0 in L0 suggested that terrestrial-derived C contributed significantly to the constitution of yolk reserves, in addition to phytoplankton-derived $\mathrm{C}$ sources.

In accordance with previous studies, from stages 1 to $4, C$. lavaretus larvae preferentially fed on copepods (Anneville et al., 2007) which were shown to be relatively poor in diatom-derived and enriched in terrestrial-derived FA. Consistently, FA profiles of larvae were impoverished in diatom-derived FAs. In larval fish from stages 1 to 4 , the terrestrial-derived $\mathrm{C} 24: 0$ and the diatom-derived C16:1n-7 represented similar percentages of total FAs $(2-3 \%)$. Values for the diatom index in C. lavaretus larvae at stage 4 were fairly similar to those of copepods, their major prey. Values for the terrestrial index were already high in L0 stages. They then decreased from L0 to L4 but remained significant, consistently with larvae feeding preferentially on C24:0-rich copepods. Hence, the growth of C. lavaretus early larval stages was only partially supported by diatom spring production peak but, for significant part, by terrestrial-derived $\mathrm{C}$.

As copepods were a poor EPA source, $C$. lavaretus larvae were depleted in EPA. This is in contrast with previous studies showing that larvae tend to retain preferentially EPA (Desvilettes et al., 1994) as an essential fatty-acid for fish larval growth. One explanation might be that, in spite of their relative deficiency in EPA, copepods provided enough EPA to meet the larvae's requirements for their development and growth in Lake Annecy at this time. In contrast, as copepods are DHA rich, larvae showed increasing DHA amounts. In stage 4, DHA reached higher amounts in larvae than in their prey. This pattern confirmed that larvae preferentially accumulate DHA (Desvilettes et al., 1994). Some of this excess DHA, however, may be provided by the desaturation of dietary FA [e.g. C22:5n-3 (Desvilettes et al., 1994) or EPA (Ballantyne et al., 2003; Zheng et al., 2005)], although enzymatic bioconversion systems might be more active in juvenile and adult fishes than in larvae (Muje, 1989). It would be crucial, in a subsequent study, to identify the major DHA sources for copepods and ultimately C. lavaretus larvae. Cryptophytes, 
dinophytes, both abundant in the nanophytoplankton size fraction at the study time, and heterotrophic protists are all candidates (Ahlgren et al., 1990; Napolitano, 1998; Bec et al., 2006).

Contrary to the initial hypothesis, the growth of $C$. lavaretus early larval stages was not only supported by the phytoplankton production peak, but terrestrial-derived $\mathrm{C}$ contributed significantly to larval fish growth. This is, however, a 1 year study. Further research is required to study how such a pattern varies between years and how it may affect $C$. lavaretus recruitment. In 2006, this pattern resulted from $C$. lavaretus larvae feeding preferentially on copepods, while secondary production was supported by both terrestrialderived and diatom-derived $\mathrm{C}$ at this time of the study year. Although this assumption would require further analyses, however, the diatom production peak in spring could eventually contribute indirectly to the copepods' secondary production if dissolved organic carbon, produced from diatom exudates or senescence, stimulates bacterial growth. Recycled diatom organic matter could then be transferred to copepods through grazing on the microbial loop and then contribute indirectly to the copepods' secondary production. Unfortunately, such a pathway might not be easily traced from fatty acid profiles.

The quality of this paper was significantly improved by reviewers' comments. We are grateful to M. T. Brett for his advice and careful corrections on the manuscript. This work was supported by a collaborative BQR-CISM B2006-26 (University of Savoie) and INRA funding. We thank M. Colon, A. Ponticelli and J.-C. Hustache for their active participation in field sampling campaigns, D. Gerdeaux for his advice and L. Laine for zooplankton counts and gut content analyses.

\section{References}

Ahlgren, G., Lundstedt, L., Brett, M. \& Forsberg, C. (1990). Lipid-composition and food quality of some freshwater phytoplankton for cladoceran zooplankters. Journal of Plankton Research 12, 809-818.

Ahlgren, G., Gustafsson, I. B. \& Boberg, M. (1992). Fatty-acid content and chemicalcomposition of fresh water microalgae. Journal of Phycology 28, 37-50.

Anneville, O., Laine, L., Benker, S., Ponticelli, A. \& Gerdeaux, D. (2007). Food habits and ontogenic changes in the diet of whitefish larvae in Lake Annecy. Bulletin français de Pêche et de Pisciculture 387, 21-33.

Ballantyne, A. P., Brett, M. T. \& Schindler, D. E. (2003). The importance of dietary phosphorus and highly unsaturated fatty acids for sockeye (Oncorhynchus nerka) growth in Lake Washington - a bioenergetics approach. Canadian Journal of Fisheries and Aquatic Sciences 60, 12-22.

Beaugrand, G., Brander, K. M., Lindley, J. A., Souissi, S. \& Reld, P. C. (2003). Plankton effect on cod recruitment in the North Sea. Nature 426, 661-662.

Bec, A., Desvilettes, C., Vera, A., Fontvieille, D. \& Bourdier, G. (2003). Nutritional value of different food sources for the benthic Daphnidae Simocephalus vetulus: role of fatty acids. Archiv für Hydrobiologie 156, 145-163.

Bec, A., Martin-Creuzburg, D. \& von Elert, E. (2006). Trophic upgrading of autotrophic picoplankton by the heterotrophic nanoflagellate Paraphysomonas sp. Limnology and Oceanography 51, 1699-1707.

Bell, M. V. \& Sargent, J. R. (1996). Lipid nutrition and fish recruitment. Marine Ecology Progress Series 134, 315-316. 
Bradford, M. J. \& Cabana, G. (1997). Interannual variability in survival rates and causes of recruitment variation. In Early Life History and Recruitment in Fish Populations (Chambers, R. C. \& Trippel, E. A., eds), pp. 470-493. London: Chapman \& Hall.

Brett, M. T., Muller-Navarra, D. C., Ballantyne, A. P., Ravet, J. L. \& Goldman, C. R. (2006). Daphnia fatty acid composition reflects that of their diet. Limnology and Oceanography 51, 2428-2437.

Burns, C. W. (1968). The relationship between body size of filter-feeding cladocera and the maximum size of particle ingested. Limnology and Oceanography 13, 675-678.

Carpenter, S. R., Pace, M. L., Cole, J. J., Van de Bogert, M., Bade, D., Bastviken, D., Gille, R. M., Hodgson, J. R., Kitchell, J. F. \& Kritzberg, E. S. (2005). Ecosystem subsidies: terrestrial support of aquatic food webs from ${ }^{13} \mathrm{C}$ addition to contrasting lakes. Ecology 86, 2737-2750.

Dalsgaard, J., St John, M., Kattner, G., Müller-Navarra, D. C. \& Hagen, W. (2003). Fatty acid trophic markers in the pelagic marine environement. In Advances in Marine Biology (Southward, A. J., Tyler, P. A., Young, C. M. \& Fuiman, L. A., eds), pp. 225-340. Amsterdam: Academic Press.

Desvilettes, C., Bourdier, G. \& Breton, J. C. (1994). Lipid class and fatty-acid composition of planktivorous larval pike Esox lucius living in a natural pond. Aquatic Living Resources 7, 67-77.

Desvilettes, C., Bourdier, G., Amblard, C. \& Barth, B. (1997). Use of fatty acids for the assessment of zooplankton grazing on bacteria, protozoans and microalgae. Freshwater Biology 38, 629-637.

Ederington, M. C., McManus, G. B. \& Harvey, H. R. (1995). Trophic transfer of fattyacids, sterols, and a triterpenoid alcohol between bacteria, a ciliate, and the copepod Acartiatonsa. Limnology and Oceanography 40, 860-867.

Farkas, T., Kariko, K. \& Csengeri, I. (1981). Incorporation of 14C-acetate into fatty acids of the Crustaceans Daphnia magna and Cyclops strenus in relation to temperature. Lipids 16, 418-422.

Ishizaki, Y., Masuda, R., Uematsu, K., Shimizu, K., Arimoto, M. \& Takeuchi, T. (2001). The effect of dietary docosahexaenoic acid on schooling behavior and brain development in larval yellowtail. Journal of Fish Biology 58, 1691-1703.

Kainz, M., Arts, M. T. \& Mazumder, A. (2004). Essential fatty acids in the planktonic food web and their ecological role for higher trophic levels. Limnology and Oceanography 49, 1784-1793.

Karlsson, J., Jonsson, A., Meili, M. \& Jansson, M. (2003). Control of zooplankton dependence on allochthonous organic carbon in humic and clear-water lakes in northern Sweden. Limnology and Oceanography 48, 269-276.

Kerfoot, W. C. \& Kirk, K. L. (1991). Degree of taste discrimination among suspensionfeeding cladocerans and copepods - implications for detritivory and herbivory. Limnology and Oceanography 36, 1107-1123.

Luczynski, M., Falkowski, S. \& Kopecki, T. (1988). Larval development in four coregonid species (Coregonus albula, C. lavaretus, C. muksun and C. peled). Finnish Fisheries Research 9.

Muje, P. (1989). Fatty-acid composition of vendace (Coregonus albula L.) muscle and its plankton feed. Comparative Biochemistry and Physiology B 92, 75-79.

Napolitano, G. E. (1998). Fatty acids as trophic and chemical markers in freshwater ecosystems. In Lipids in Freshwater Ecosystems (Arts, M. T. \& Wainman, B. C., eds), pp. 21-44. New York, NY: Springer Verlag.

Parrish, C. C., Abrajano, T. A., Budge, S. M., Helleur, R. J., Hudson, E. D., Pulchan, K. \& Ramos, C. (2000). Lipids and phenolic biomarkers in marine ecosystems: analysis and applications. In The Handbook of Environmental Chemistry (Wangersky, P., ed.), pp. 193-223. Berlin: Springer.

Perga, M.-E. \& Gerdeaux, D. (2005). 'Are fish what they eat' all year long? Oecologia 144, 598-606.

Perga, M.-E., Kainz, M., Matthews, B. \& Mazumder, A. (2006). Carbon pathways to zooplankton: insights from the paired use of stable isotope and fatty acid biomarkers. Freshwater Biology 51, 2041-2051. 
Platt, T., Fuentes-Yaco, C. \& Frank, K. T. (2003). Spring algal bloom and larval fish survival. Nature 423, 398-399.

Pohl, P. \& Zurheide, F. (1979). Fatty acids and lipids of marine algae and the control of their biosynthesis by environmental factors. In Marine Algae in Pharmaceutical Science (Hoppe, H. A., Leuring, T. \& Tanaka, Y., eds), pp. 473-523. Berlin: Walter de Gruiyter.

Rossi, S., Sabates, A., Latasa, M. \& Reyes, E. (2006). Lipid biomarkers and trophic linkages between phytoplankton, zooplankton and anchovy (Engraulis encrasicolus) larvae in the NW Mediterranean. Journal of Plankton Research 28, 551-562.

Sargent, J., Parkes, R. J., Mueller-Harvey, I. \& Henderson, R. J. (1987). Lipid biomarkers in marine ecology. In Microbes in the Sea (Sleigh, M. A., ed.), pp. 119-138. Chichester: Ellis Horwood Ltd.

Sargent, J. R., Bell, M. V. \& Henderson, R. J. (1995). Protists as sources of (n-3) polyunsaturated fatty acids for vertebrate development. In Protistological Actualities, Proceedings of the 2nd European Congress on Protistology and the 8th European Conference on Ciliate Biology (Brugerolle, G. \& Mignot J. P., eds), pp. 54-64. Aubiere Cedex: J. Senaud, Biologie des Protistes.

Sargent, J., McEvoy, L., Estevez, A., Bell, G., Bell, M., Henderson, J. \& Tocher, D. (1999). Lipid nutrition of marine fish during early development: current status and future directions. Aquaculture 179, 217-229.

SILA (2007). Suivi scientifique du Lac d'Annecy, rapport 2006. Annecy: SILA (Syndicat Intercommunal du Lac d'Annecy)-INRA Ed.

St John, M. A. \& Lund, T. (1996). Lipid biomarkers: linking the utilization of frontal plankton biomass to enhanced condition of juvenile North Sea cod. Marine Ecology Progress Series 131, 75-85.

St John, M. A., Clemmesen, C., Lund, T. \& Koster, T. (2001). Diatom production in the marine environment: implications for larval fish growth and condition. ICES Journal of Marine Science 58, 1106-1113.

Sun, M. Y., Shi, W. \& Lee, R. F. (2000). Lipid-degrading enzyme activities associated with distribution and degradation of fatty acids in the mixing zone of Altamaha estuarine sediments. Organic Geochemistry 31, 889-902.

Ütermohl, H. (1958). Zur Vervollkommung der quantitativen Phytoplankton-methodik. Mitteilungen internationale Vereinigung für theoretische und angewändte Limnologie 9, 1-38.

Wetzel, R. G. \& Likens, G. E. (2000). Limnological Analyses. New York, NY: Springer.

Zheng, X. Z., Torstensen, B. E., Tocher, D. R., Dick, J. R., Henderson, R. J. \& Bell, J. G. (2005). Environmental and dietary influences on highly unsaturated fatty acid biosynthesis and expression of fatty acyl desaturase and elongase genes in liver of Atlantic salmon (Salmo salar). Biochimica et Biophysica Acta-Molecular and Cell Biology of Lipids 1734, 13-24. 